\title{
An ex vivo perfused ventilated murine lung model suggests lack of acute pulmonary toxicity of the potential novel anticancer agent (-)-englerin A
}

\author{
Christian Schremmer ${ }^{1} \cdot$ Dirk Steinritz $^{2}$ (D) Thomas Gudermann $^{1} \cdot$ David J. Beech ${ }^{3}$. Alexander Dietrich ${ }^{1}$
}

Received: 10 November 2021 / Accepted: 20 January 2022 / Published online: 14 February 2022

(c) The Author(s) 2022

\begin{abstract}
(-)-Englerin A (EA), a potential novel anti-cancer drug, is a potent selective activator of classical transient receptor potential 4 and 5 (TRPC4, TRPC5) channels. As TRPC4 channels are expressed and functional in the lung endothelium, possible side effects such as lung edema formation may arise during its administration. Well-established in vivo rodent models for toxicological testing, however, rapidly degrade this compound to its inactive derivative, englerin $\mathrm{B}$. Therefore, we chose an ex vivo isolated perfused and ventilated murine lung (IPVML) model to detect edema formation due to toxicants, which also reduces the number of incriminating animal experiments required. To evaluate the sensitivity of the IPVML model, short-time (10 min) drops of the $\mathrm{pH}$ from 7.4 down to 4.0 were applied, which resulted in linear changes of tidal volumes, wet-to-dry weight ratios and incorporation of FITC-coupled dextran particles from the perfusate. As expected, biological activity of EA was preserved after perfusion in the IPVML model. Concentrations of 50-100 nM EA continuously perfused through the IPVML model did not change tidal volumes and lung weights significantly. Wet-to-dry weight ratios were increased after perfusion of $100 \mathrm{nM}$ EA but permeation of FITC-coupled dextran particles from the perfusate to the lung tissues was not significantly different. Therefore, EA shows little or no significant acute pulmonary toxicity after application of doses expected to activate target ion channels and the IPVML is a sensitive powerful ex vivo model for evaluating acute lung toxicity in accordance with the $3 \mathrm{R}$ rules for animal experimentation.
\end{abstract}

Keywords Anti-cancer drug · Lung edema $\cdot$ Classical transient receptor potential 4 and 5 (TRPC4, TRPC5) - Tidal volume $\cdot$ Wet-to-dry weight ratio $\cdot$ FITC-dextran permeation assay

$\begin{array}{ll}\text { Abbreviations } \\ {\left[\mathrm{Ca}^{2+}\right]_{\mathrm{i}}} & \begin{array}{l}\text { Intracellular } \mathrm{Ca}^{2+} \text { concentration } \\ \text { EA }\end{array} \\ \text { FITC } & \text { Fluorescein isothiocyanate } \\ \mathrm{h} & \text { Hour(s) } \\ \text { IPVML } & \text { Isolated perfused and ventilated murine lung } \\ \text { min } & \text { Minute(s) } \\ \text { TRPC4/5 } & \text { Classical transient receptor potential 4/5 }\end{array}$

Alexander Dietrich

alexander.dietrich@1rz.uni-muenchen.de

1 Walther Straub Institute of Pharmacology and Toxicology, Member of the German Center for Lung Research (DZL), Medical Faculty, LMU-Munich, Nussbaum Str. 26, 80336 Munich, Germany

2 Bundeswehr Institute of Pharmacology and Toxicology, Neuherbergstraße 11, 80937 Munich, Germany

3 School of Medicine, University of Leeds, LIGHT Building, Clarendon Way, Leeds LS2 9JT, England, UK

\section{Introduction}

(-)-Englerin A (EA) is a guaiane sesquiterpene originally isolated from the bark of the plant phyllanthus engleri from southern Africa (Wu et al. 2017). This natural product effectively inhibits growth of several kidney and breast cancer cell lines with an $\mathrm{IC}_{50}$ of $35-50 \mathrm{nM}$, while their non-tumorigenic counterparts were only affected at higher concentrations $(>10 \mu \mathrm{M})$ (Sourbier et al. 2013). Further analysis of cell lines revealed that EA is a potent activator of TRPC4 and TRPC5 channels and TRPC4 expression correlates with EA sensitivity of cancer cell lines (Akbulut et al. 2015; Carson et al. 2015). Both channels are members of the seven classical transient receptor potential family, which form homoand heterotetrameric unselective cation channel. Death of synovial sarcoma (SW982) cells in vitro after application of EA $(10 \mathrm{nM})$ occurs by $\mathrm{Na}^{+}$influx through TRPC $1 / 4$ heteromeric channels and is further increased by inhibition of $\mathrm{Na}^{+} /$ $\mathrm{K}^{+}$-ATPase removing excess intracellular $\mathrm{Na}^{+}$ions (Ludlow 
et al. 2017; Muraki et al. 2017). Application of EA ( $2 \mathrm{mg} / \mathrm{kg}$ body weight) resulted in a significant reduction in locomotor activity for about $1 \mathrm{~h}$ as a potential side effect (Cheung et al. 2018). TRPC4- and TRPC5-deficient mice were partially and TRPC $4 / 5$ double knock-out mice were fully protected from this adverse EA effect (Cheung et al. 2018). In contrast to TRPC1/5, TRPC1/4 channels were also detected in murine lung endothelium (Sundivakkam et al. 2012) and are responsible for thrombin-induced lung edema, which is reduced in TRPC4-deficient lungs (Tiruppathi et al. 2002). Analysis of pulmonary toxicity of EA, however, turned out to be complicated for two reasons. First, intravenous (IV) injection of EA doses of $>1 \mathrm{mg} / \mathrm{kg}$ body weight were lethal in rats and second EA was rapidly degraded with an estimated half time of $\approx 15$ min into the inactive compound englerin $B$ in mice and rats by serum esterases, but not in human serum (Carson et al. 2015). The authors observed labored breathing in mice after subcutaneous injection of EA (5 mg/kg body weight) (Carson et al. 2015). It was, however, unclear, if this side effect was due to EA, which never exceeded levels of $12 \mathrm{nM}$ in blood, or its metabolite englerin $\mathrm{B}$, which was rapidly detected after application in rodents but not in humans. Therefore, we employed a new ex vivo model for evaluating acute EA toxicity using the isolated, perfused and ventilated murine lung (IPVML) offering numerous advantages compared to an in vivo system. We hypothesized that due to the absence of esterase in the perfusate EA is not degraded and defined doses can be applied. Lung parameters are analyzed in real time during the experiment without high stress levels in a living mouse. Moreover, wet to dry weight ratios and invasion of perfused fluorescein isothiocyanate (FITC)-dextran particle in the lung tissue can be quantified after the experiment. The applicability of the model was evaluated after applying short-time graduated $\mathrm{pH}$ changes from $\mathrm{pH} 7.4$ to $\mathrm{pH} 4.0$, which resulted in significant linear changes of values for wet-to-dry ratios and tidal volumes. Most interestingly, EA showed no significant changes in lung parameters and edema formation upon application of 50 or $100 \mathrm{nM}$ EA [fivefold or tenfold of the $\mathrm{EC}_{50}$ values obtained in vitro experiments with SW982 cells (Muraki et al. 2017)] in comparison to control mice receiving electrolyte solution only.

\section{Materials and methods}

\section{Chemicals}

Electrolyte solution was prepared by the Apotheke Klinikum der Universität München: $7.19 \mathrm{~g}$ sodium chloride, $0.33 \mathrm{~g}$ potassium chloride, $0.27 \mathrm{~g}$ magnesium hexahydrate, $0.36 \mathrm{~g}$ calcium chloride dihydrate, $0.15 \mathrm{~g}$ potassium dihydrogen orthophosphate, $2.67 \mathrm{~g}$ glucose monohydrate, $51.28 \mathrm{~g}$ hydroxyethyl starch 200000/05 ad $1000 \mathrm{ml}$ with aqua ad injectabilia, use $0.1848 \mathrm{mg} / \mathrm{ml}$ sodium hydrogen carbonate to adjust $\mathrm{pH}$ to 7.4. (-)-Englerin A (EA) was purchased from Roth (6492.1, Karlsruhe, Germany), Fluorescein isothiocyanate was provided from Sigma (90718, average Mw 70 kD, Taufkirchen, Germany) and GeneJuice ${ }^{\circledR}$ Transfection Reagent was ordered from Sigma (70967, Taufkirchen, Germany). EA stock solution was prepared at $100 \mathrm{mM}$ in the Novartis approved standard solution for all in-life preclinical evaluations containing 5\% ethanol, $10 \%$ polyethylene glycol 300 (Sigma Aldrich), 5\% cremophor EL (Merck Chemicals Ltd), and 80\% PBS as described before (Carson et al. 2015; Cheung et al. 2018). The final concentration of this solution was $0.0001 \%$ in the electrolyte buffer.

\section{Isolated perfused and ventilated murine lung (IPVML)}

IPVML were prepared from C57BL/6 mice as described previously (Weissmann et al. 2006, 2012). Mice were anesthetized and anticoagulated by i.p. injection of ketamine (100 mg/kg body weight (bw), Covetrus, Hamburg, Germany), xylazine ( $7 \mathrm{mg} / \mathrm{kg}$ bw, Covetrus, Hamburg, Germany) and with heparin (500 U/kg bw, Meditech Vertriebs $\mathrm{GmbH}$, Parchim, Germany). Lungs were transferred from the body into an artificial glass thorax, ventilated with room air (positive pressure ventilation, $90 \mathrm{breath} / \mathrm{min}$ ) and perfused with the blood-free electrolyte solution heated to $37{ }^{\circ} \mathrm{C}$. Upon reaching a final flow rate of $2 \mathrm{ml} / \mathrm{min}$ ventilation was switched to negative pressure (90 breath/min, $50 \%$ inspiration time) and a deep inspiration was initiated every $5 \mathrm{~min}$. After $15 \mathrm{~min}$ of perfusion, an external reservoir $(20 \mathrm{ml})$ containing electrolyte solution and indicated compounds $(\mathrm{pH}$ drop or EA) was connected and after an additional 4 min the perfusion circuit, which then contained only perfusion solution of the external reservoir, was closed. The $\mathrm{pH}$ was continuously measured in the external reservoir and adjusted, if necessary, in the first 10 min by a pH meter (WTW inoLab ${ }^{\circledR}$ pH 7110, Weilheim, Germany). All data were transmitted to a computer and constantly monitored with the Pulmodyn software (Hugo Sachs Elektronik, March-Hugstetten, Germany). During perfusion with FITC-dextran particles, the solution was protected from light to avoid bleaching.

\section{Wet-to-dry weight ratios}

For wet-to-dry weight ratios lung weight was quantified directly after the experiment (wet weight) and after drying at $50{ }^{\circ} \mathrm{C}$ for $48 \mathrm{~h}$ (dry weight). 
Fig. 1 Experimental setup of the isolated perfused ventilated murine lung (IPVML) model (A). A freshly isolated lung heart preparation was perfused through the pulmonary artery and ventilated through the trachea. Twenty ml of solutions with Englerin A (EA, 50, $100 \mathrm{nM}$ ) or equilibrated to $\mathrm{pH}$ $6.0, \mathrm{pH} 5.0$ and $\mathrm{pH} 4.0$ were relased from a reservoir in the perfusion solution. Lung weight and tidal volumes were continously quantified by in built weighing scales or the software, respectively. Time line of the experiment (B). After $15 \mathrm{~min}$ perfusion EA in solution or solutions of decreased $\mathrm{pH}$ were released from the reservoir. The $\mathrm{pH}$ was continously measured in the reservoir and adjusted for $10 \mathrm{~min}$, if necessary. The outlet was closed after 4 min and the perfusion solutions circulated for another $50 \mathrm{~min}$ in a closed circuit

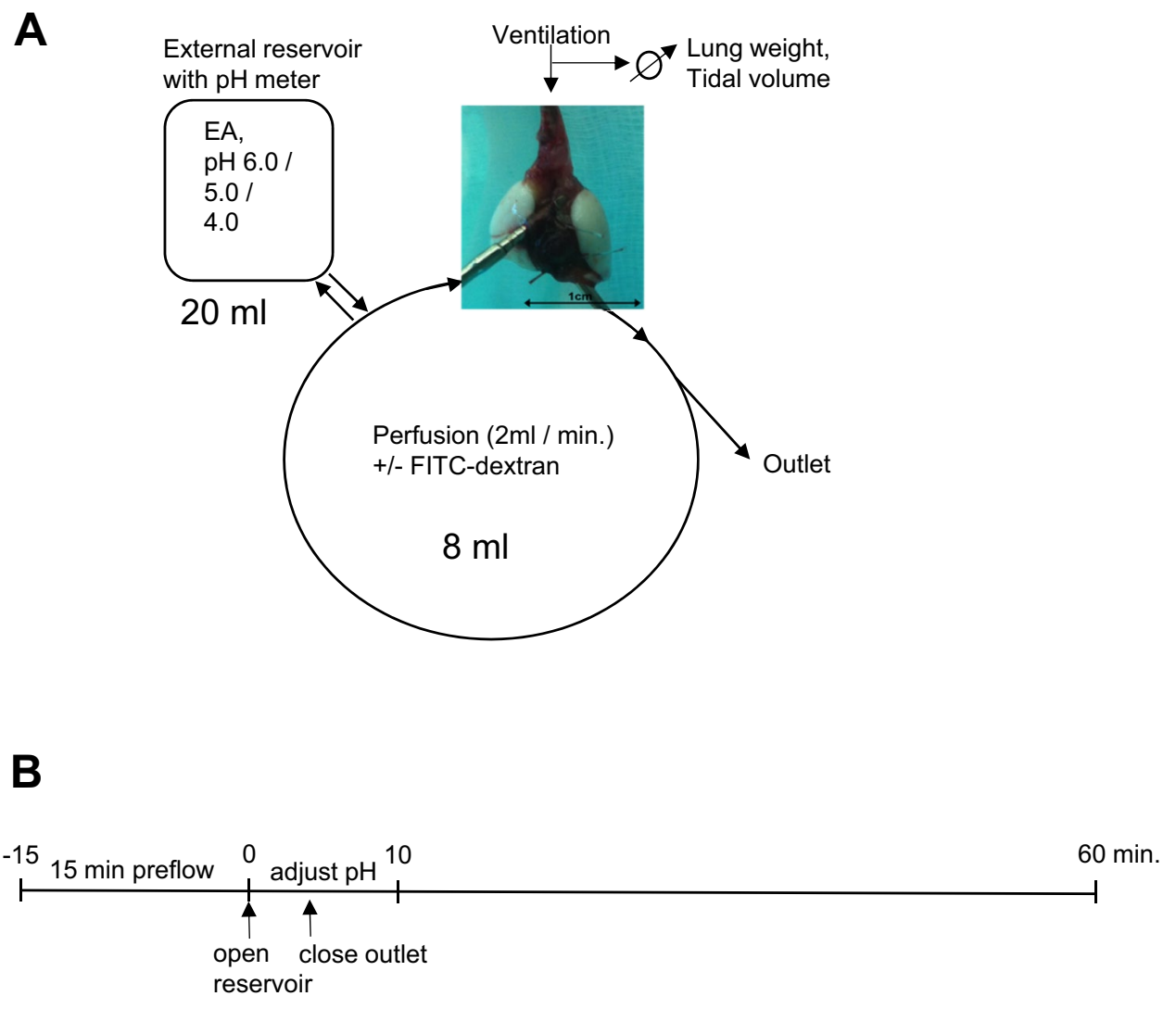

\section{$\mathrm{Ca}^{2+}$ imaging}

HEK293T cells were grown on $\varnothing 25 \mathrm{~mm}$ coverslips for $24 \mathrm{~h}$ and transfected with a TRPC $4 \beta 1$ cDNA in a pIRES2 plasmid containing an eGFP cDNA under the control of the internal ribosome entry site (IRES) using GeneJuice ${ }^{\circledR}$ solution as described by the manufacturer for $24 \mathrm{~h}$. Cells were washed and loaded with FURA-2-AM ( $2 \mu \mathrm{M}$, F0888, Sigma, Taufkirchen, Germany) in 0,1\% BSA in HEPES buffered HBSS at $37{ }^{\circ} \mathrm{C}$ for $30 \mathrm{~min}$. Coverslips were washed with HEPES buffered HBSS and placed under a microscope in a recording chamber with a $500 \mu \mathrm{l}$ volume. An increase in intracellular $\mathrm{Ca}^{2+}$ was recorded using a Leica DFC9000 GT camera coupled to an inverted microscope (DMi8, Leica, Wetzlar, Germany) with an 40x/0.85 oil immersions objective at 340 and $380 \mathrm{~nm}$ for quantification of $\left[\mathrm{Ca}^{2+}\right]_{i}$ as described (Bendiks et al. 2020).

\section{Lung histology}

Following perfusion with FITC-dextran particles mouse lungs were incubated in $4 \%(\mathrm{w} / \mathrm{v})$ paraformaldehyde in PBS and processed for embedding in O.C.T ${ }^{\mathrm{TM}}$ Compound (Tissue-Tek $^{\circledR}$, Sakura Finetek, Umkirch, Germany) as described before (Weber et al. 2020). Cryo-embedded lungs were cut in $10 \mu \mathrm{m}$ sections using a cryotome (CM1900, Leica,
Wetzlar, Germany) and mounted on glass slides in Dako Omnis Fluorescence mounting medium (GM30411-2, Agilent Technologies, Santa Clara, USA). Lung sections were analyzed using both a confocal microscope (LSM 880, Carl Zeiss Jena, Germany) and a fluorescence scanner (Typhoon Trio, GE Healthcare, Solingen, Germany).

\section{Data analysis}

Data analysis was performed using R and data were plotted using GraphPad Prism 9. Used statistical tests and $p$ values are indicated in the figure legends.

\section{Results}

\section{Experimental setup for detection of acute lung toxicity by ex vivo isolated perfused ventilated murine lungs (IPVML)}

The experimental setup and the timeline for the detection of acute lung toxicity in the IPVML by edema formation are depicted in Fig. 1A, B, respectively. After mounting, a freshly isolated murine lung was ventilated and perfused with an open outlet for $15 \mathrm{~min}$. A $20 \mathrm{ml}$ reservoir containing the substance to be tested [EA $(50,100 \mathrm{nM})$ ) or 
perfusion solution of decreased $\mathrm{pH}$ values $(\mathrm{pH}$ 6.0, 5.0 and 4.0)] replaced the perfusion solution and $\mathrm{pH}$ values were adjusted for $10 \mathrm{~min}$ in the external reservoirs. The outlet was closed and lungs were continuously perfused with or without FITC-dextran particles and monitored for an additional $50 \mathrm{~min}$. Lung weight and tidal volume were constantly quantified during the experiment, while wet-to-dry weight ratios and invasion of FITC-dextran particles in the tissues were analyzed after the experiment.

\section{Validation of the IPVML for detection of acute lung toxicity induced by short drops of the $\mathrm{pH}$}

To evaluate the sensitivity of the IPVML model, we applied solutions with a decreased $\mathrm{pH}$ (pH 6.0, $\mathrm{pH} 5.0$ and $\mathrm{pH} 4.0)$. Significant increases in lung weight due to an acute formation of lung edema during the experiment were only detected for a short-time drop to $\mathrm{pH} 4.0$, but not for $\mathrm{pH} 5.0$ or $\mathrm{pH}$ 6.0 (Fig. 2A). A linear decrease in tidal volumes with dropping $\mathrm{pH}$ values was, however, obvious during the experiment (Fig. 2B). Wet-to-dry weight ratios after the experiment were linearly increased for transient drops to $\mathrm{pH} 6.0, \mathrm{pH} 5.0$ and $\mathrm{pH} 4.0$ (Fig. 2C). Therefore, short-time changes in $\mathrm{pH}$ correlate with a linear increase in wet-to-dry weight ratios and a linear decrease in tidal volumes in the IVPML model. The experimental setup is, therefore, suitable and sensitive enough to detect acute lung edema in a linear fashion.

\section{Biological activity of (-)-englerin A (EA) before and after perfusion in the IPVML}

The biological activity of EA (Fig. 3A) was quantified by $\mathrm{Ca}^{2+}$ imaging of HEK $293 \mathrm{~T}$ cells heterologously expressing TRPC4 channels after transfection with a pIRES plasmid carrying cDNAs for TRPC4 and an enhanced green fluorescent protein (eGFP). EA (50 and $100 \mathrm{nM}$ ) before and after the experiment ( $1 \mathrm{~h}$ perfusion) was able to increase intracellular $\mathrm{Ca}^{2+}\left(\left[\mathrm{Ca}^{2+}\right]_{\mathrm{i}}\right)$ levels by opening TRPC 4 channels and $\mathrm{Ca}^{2+}$-influx through the channel pore, while non-transfected cells show only minor changes in $\left[\mathrm{Ca}^{2+}\right]_{\mathrm{i}}$ (Fig. 3B-E). Our results indicate a preserved biological activity of EA after $1 \mathrm{~h}$ perfusion in the IPVML model.

\section{Evaluation of acute lung toxicity induced by EA in the IPVML}

Changes in lung weight during $1 \mathrm{~h}$ perfusion of EA (50 and $100 \mathrm{nM}$ ) in comparison to electrolyte solution are depicted in Fig. 4A. No significant differences were observed. The same was true for the analysis of tidal volumes during the experiment (Fig. 4B). Wet-to-dry weight ratios showed, in comparison to short drops in $\mathrm{pH}$, a small but significant
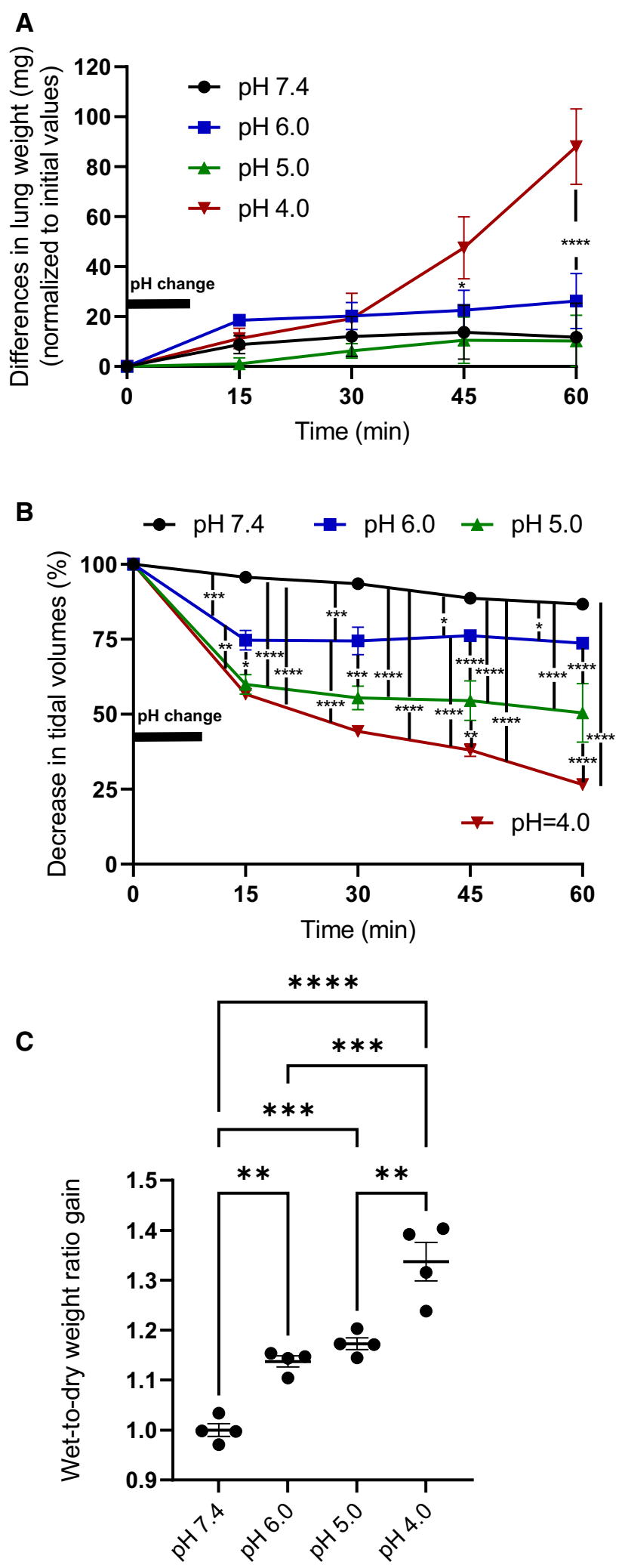

Fig. 2 Lung weight gain after a short (10 min) drop of the $\mathrm{pH}$ to 6.0, 5.0 and 4.0 (A). Changes in tidal volumes after a short $(10 \mathrm{~min})$ drop of the $\mathrm{pH}$ to 6.0 , 5.0 and 4.0 (B). Increases in wet-to-dry weight ratios after a short (10 $\mathrm{min})$ drop of the $\mathrm{pH}$ to $6.0,5.0$ and 4.0 were quantified after the experiment $(\mathbf{C})$. Data are means \pm SEM. $p$ values were calculated by two way ANOVA and are indicated by asterisks $\left(*, p<0.05 ; 2^{*}, p<0.01 ; 3^{*}, p<0.001,4^{*}, p<0.0001\right)$ 
<smiles>CC(C)[C@@]12CC(OC(=O)CO)[C@]3(C)O[C@@]14C(OC(=O)/C=C/c1ccccc1)C2C3CC[C@@H]4C</smiles>

B

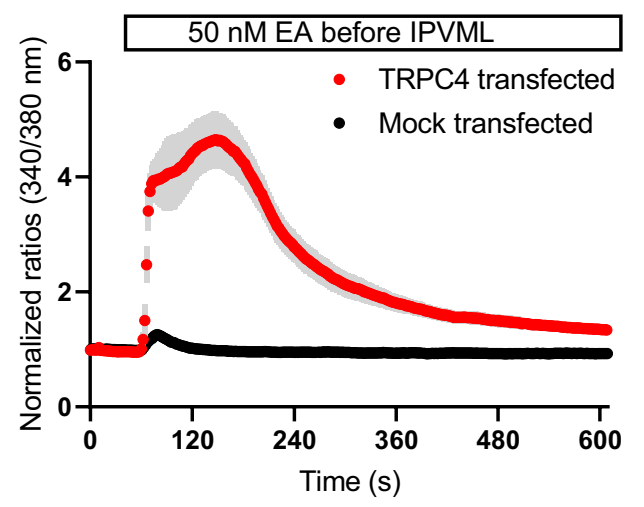

D

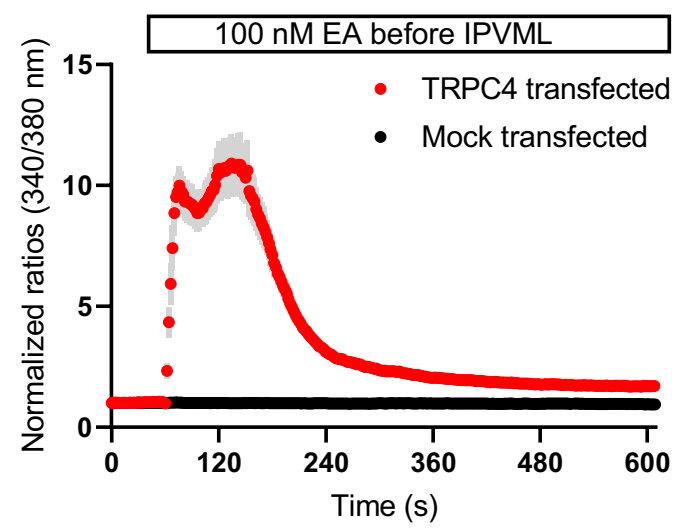

Fig. 3 Structural formula of (-)-englerin A (EA, provided by the manufacturer, see www.carlroth.com, A) and $\mathrm{Ca}^{2+}$ imaging experiments of HEK 293T cells heterologously expressing TRPC4 channels (TRPC4 transfected) or mock-transfected controls after application of

increase after application of EA (100 nM), which was not detectable for the lower concentration (50 nM) (Fig. 4C).
C

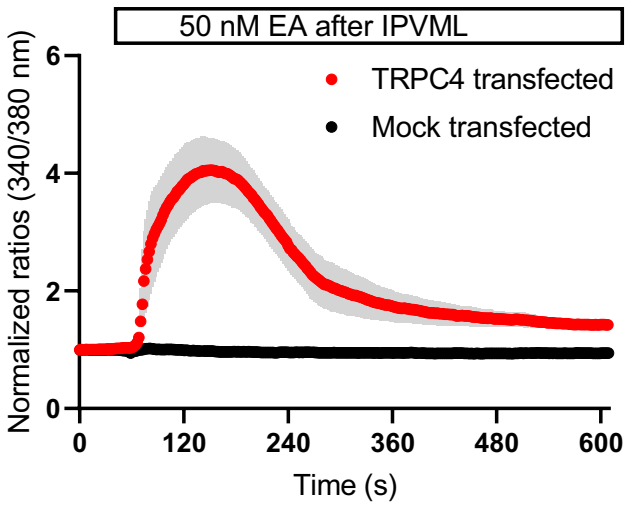

$\mathbf{E}$

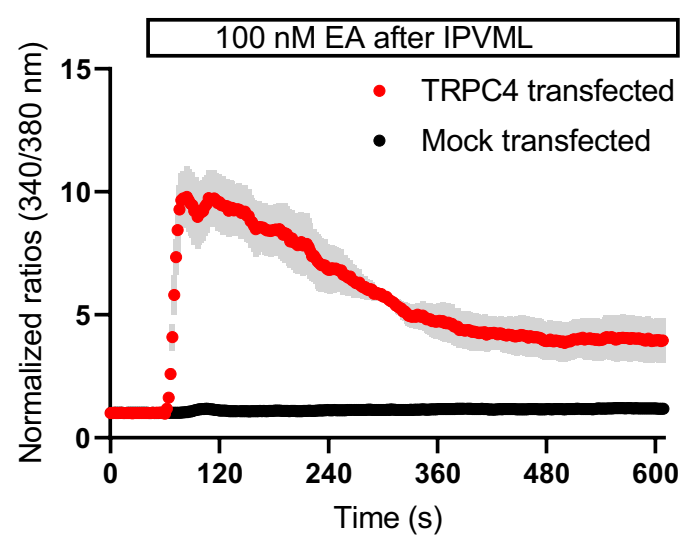

EA $(50 \mathrm{nM}, 100 \mathrm{nM})$ before and after $1 \mathrm{~h}$ perfusion in the IPVLM model. One representative experiment $(n>3$ cells) out of three is shown (B-E)

\section{Quantification of lung permeability by tissue permeation of FITC-dextran particles in the IPVML}

Endothelial and tissue permeabilty is significantly increased after exposure of toxicants from the vascular side. To quantify tissue permeation of liquids and invading cells fluorescein isothiocyanate (FITC)-coupled dextran particles 

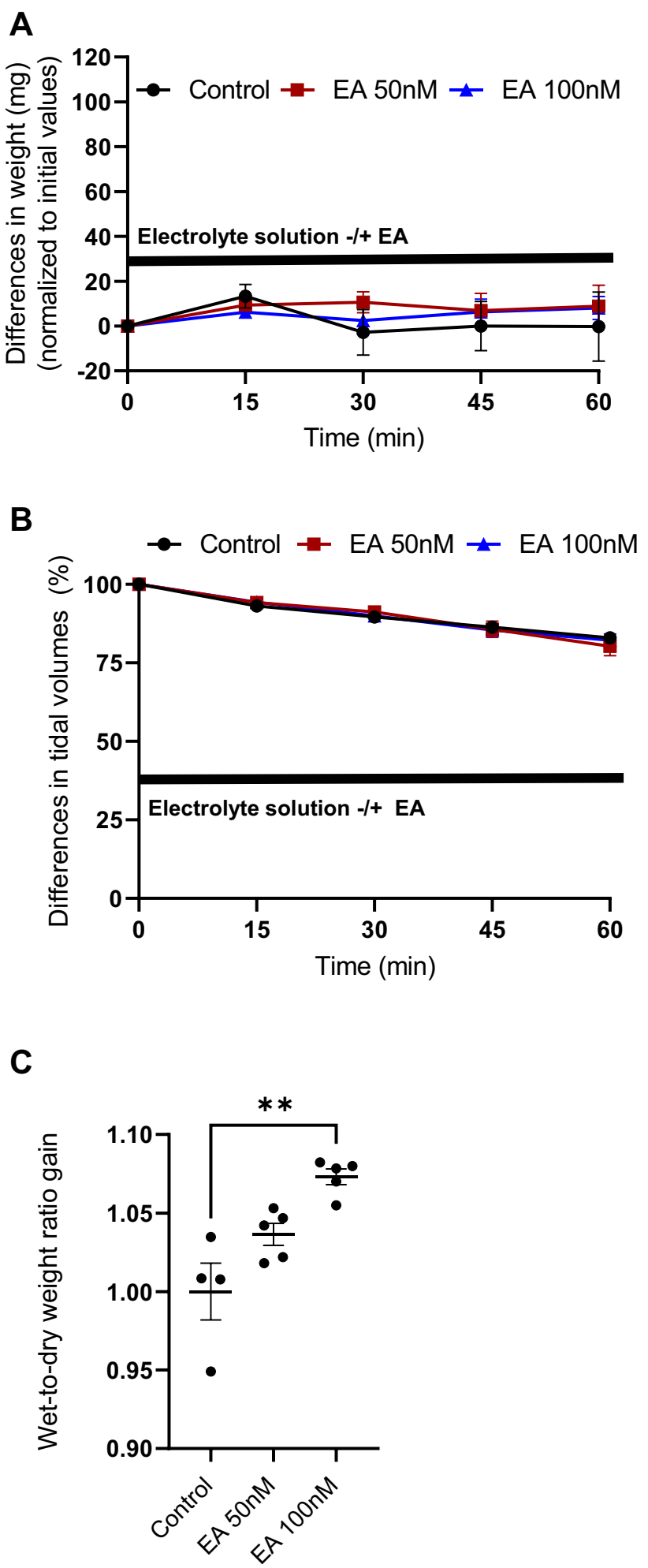

Fig. 4 Lung weight gain after application of (-)-englerin A (EA, 50 and $100 \mathrm{nM})(\mathbf{A})$. Changes in tidal volumes after application of EA (50 and $100 \mathrm{nM})(\mathbf{B})$. Increases in wet-to-dry weight ratios after after application of EA (50 and $100 \mathrm{nM})(\mathbf{C})$. Data are means \pm SEM. $p$ values were calculated by two way ANOVA and are indicated by asterisks $\left(*, p<0.05 ; 2^{*}, p<0.01\right)$ are used in cell biology and in vivo animal experiments (Thorball 1981). To test if our model is also able to detect increases in tissue permeabilty in a linear fashion, we added FITC-dextran particles in the perfusion solution during the preflow and analysed whole lungs by confocal laser scanning microscopy and by a laser scanning platform. Tissues after a short drop to $\mathrm{pH} 4.0$ incorporated a significant higher amount of FITC-dextran particle than tissues perfused with control solution of a $\mathrm{pH} 7.4$ as shown in overlay images in Fig. 5A. To quantify fluorescence in tissues without a selection bias, we scanned whole lungs on a laser scanning platform as shown in Fig. 5B. Integrated fluorescent values normalized to values of non-perfused lungs are shown in Fig. 5C. Short-time pH drops caused a significant linear increase in incorporation of FITC-dextran particels compared to EA and electrolyte solution-only perfused mouse lungs. Therefore, this ex vivo lung model is also suitable to detect higher tissue permeability after application of toxicants by permeation of FITC-dextran particles.

\section{Discussion}

EA is a promising anti-cancer compound inhibiting tumor growth of several kidney (Ratnayake et al. 2009) (Akbulut et al. 2015), breast cancer (Grant et al. 2019) and synovial carcinoma cell lines (Muraki et al. 2017). Its toxicological evaluation in rodents, however, is complicated for two reasons. Intravenous injections of EA ( $2 \mathrm{mg} / \mathrm{kg}$ body weight) were lethal to rats and after subcutaneous application EA was rapidly degraded into the inactive englerin $B$ in mice and rats, while it remains stable in humans (Carson et al. 2015). Therefore, we choose the IPVML model as an ex vivo approach to evaluate acute pulmonary toxicity of EA independently from the mode of application and degradation. We first tested its sensitivity by short drops of the $\mathrm{pH}$ of the perfusion medium from $\mathrm{pH} 7.4$ to $\mathrm{pH}$ 4.0. These $\mathrm{pH}$ changes can be observed in asthma patients after accumulation of $\mathrm{CO}_{2}$ in their blood due to their inability to exhale or by infusion of acids (Richardson et al. 1961). Moreover, metabolic acidosis and septic shock also decrease $\mathrm{pH}$ values in the blood (Mizock and Falk 1992). Significant linear increases were observed for wet-to-dry weight ratios (Fig. 2C), while tidal volumes decreased (Fig. 2B) after a stepwise drop in $\mathrm{pH}$ to 4.0. Lung edema formation quantified by an increase in lung weight during perfusion and ventilation were only detected after a drop to $\mathrm{pH} 4.0$, while decreases to $\mathrm{pH} 5.0$ and 6.0 did not induce immediate changes in lung weight (Fig. 2A). While small drops in $\mathrm{pH}$ to 6.5 did not change intracellular $\mathrm{pH}$ values significantly in endothelial cells of the rat aorta but increase intracellular NO concentrations (Capellini et al. 2013), large decreases in $\mathrm{pH}$ values may damage endothelial cells and increases endothelial 
Fig. 5 Tissue permeation of fluorescein isothiocyanate (FITC) dextrane particle after perfusion of lungs at $\mathrm{pH} 7.4$ and after a short (10 min) drop of the $\mathrm{pH}$ to 4.0. Two representative overlays of FITC fluorescence and coresponding differential interference contrast (DIC) images showing lung tissues after perfusion of electrolyte solution ( $\mathrm{pH} \mathrm{7.4)} \mathrm{and}$ after a short (10 $\mathrm{min})$ drop in $\mathrm{pH}$ (pH 4.0) are depicted (A). Two representative scans from total lungs at $\mathrm{pH} 7.4$ and after a short (10 min) drop of the $\mathrm{pH}$ to 4.0 (B). Normalized integrated densities of lungs after a short (10 min) drop of the $\mathrm{pH}$ to 6.0 , 5.0 and 4.0 or perfused with EA (50 and $100 \mathrm{nM}$ ) were normalized to lungs perfused with electrolyte solution at $\mathrm{pH} 7.4$ and plotted as columns. Data are means \pm SEM. $p$ values were calculated by two way ANOVA and are indicated by asterisks $(*, p<0.05)$
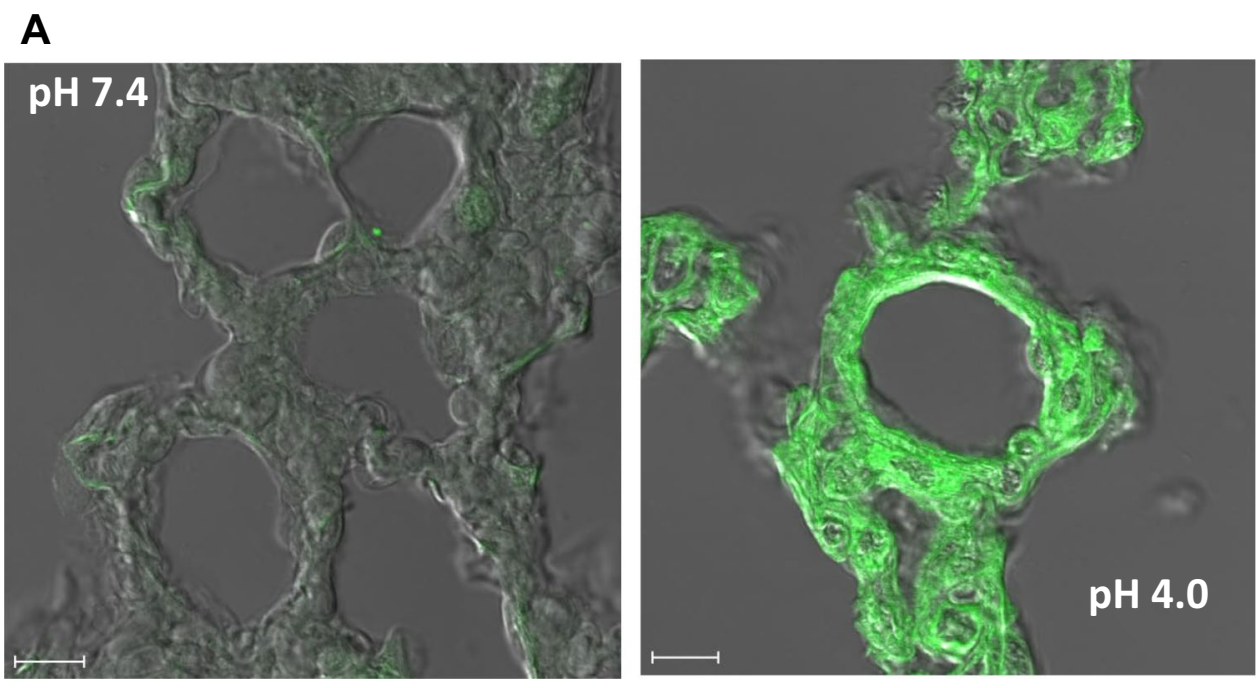

B

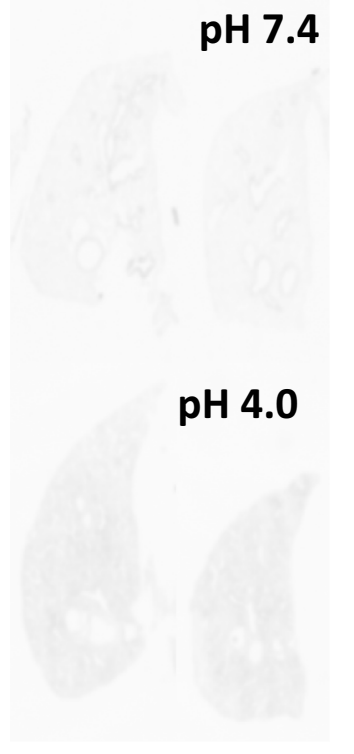

c

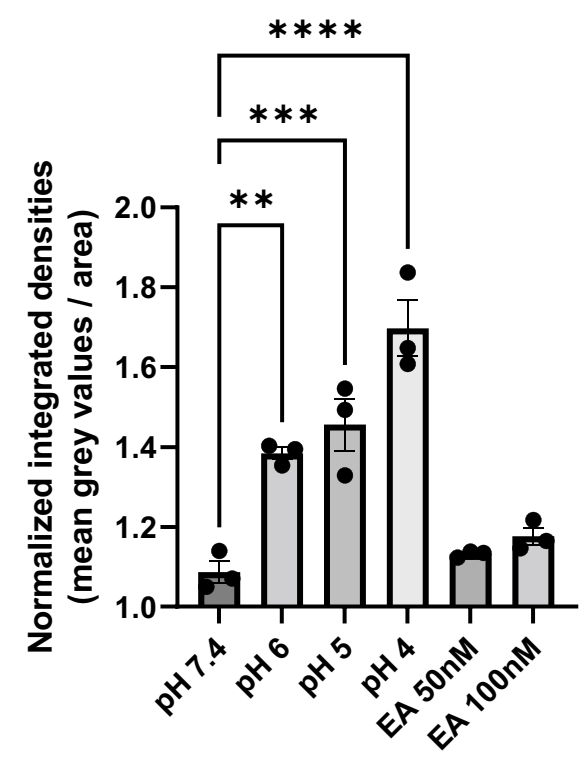

permeability. As a consequence flooding of alevoli by protein rich fluid, increases lung weight and reduces tidal volumes. Therefore, the ex vivo IPVML model realistically maps the in vivo situation of acute lung toxicity by quantifying edema formation due to a transient decreased $\mathrm{pH}$.

The biological activity of EA was tested before and after $1 \mathrm{~h}$ perfusion in the IPVML model by application to HEK 293T cells heterologously expressing TRPC4 channels or control cells. EA induced significant increases in $\left[\mathrm{Ca}^{2+}\right]_{\mathrm{i}}$ as already described (Akbulut et al. 2015) even after $1 \mathrm{~h}$ of perfusion in the IPVML model in comparison to control cells (Fig. 3A-D). As expected EA is still active and supposedly not degraded to the inactive englerin $\mathrm{B}$ in our perfusion solution as enzymes, such as esterases, which might degrade EA in rodents in vivo (Carson et al. 2015), may not be present in the IPVML model.

Tidal volumes and lung weights correlating with lung edema formation were not changed during the experiment (Fig. 4A, B) using EA for perfusion in concentrations of 50 and $100 \mathrm{nM}$, while wet-to-dry weight ratios after the experiments were significantly increased after application of 100 nM EA (Fig. 4C).

However, histological analysis of lung sections after perfusion with FITC-dextran particle revealed a similar linear increase in the incorporation of these particles in the lung tisues by transient drops of the $\mathrm{pH}$, while both concentrations of EA were not able to change fluorescence intensities significantly (Fig. 5C). Therefore, a significant change in edema formation as detected in wet-to-dry weight ratios 
after perfusion with $100 \mathrm{nM}$ EA was not confirmed in these experiments.

An overall comparison of the parameters collected in the IPVML model places tidal volumes, wet-to-dry weight ratios and FITC-dextran tissue distribution as the most sensitive values for detection of acute lung toxicity after a short $\mathrm{pH}$ drop, while lung weight changes during perfusion were only able to detect a major change in $\mathrm{pH}$ from 7.4 to 4.0.

In light of an expression of TRPC4 channels in the lung endothelium and their identified ability to increase endothelial permeabilty after activation of protease-activated receptors (PAR) by thrombin (Tiruppathi et al. 2002), our results with the highly specific TRPC4 activator EA are somewhat surprising. Except for changes in the wet-to-dry weight ratios after perfusion with $100 \mathrm{nM}$ EA, we detected no differences in edema formation after application of EA in comparison to electrolyte solution as control. This discrepancy may be due to a close clustering of PAR together with TRPC4 channels in calveolar, such as compartments, which are not easily accessible for EA from the perfusate. This hypothesis needs to be further studied in the future.

In summary, the IPVML model is suitable to evaluate acute pulmonary toxicity of drug candidates by quantification of lung edema formation independently of drug application and metabolism. In the future numerous already established gene-deficient mouse models may also be used to identify toxicant sensors in the lung by this method. Moreover, this ex vivo model eliminates stress in mice after in vivo application of drugs and is, therefore, an important refinement according to the $3 \mathrm{R}$ ethical guidelines of animal experimentation.

Acknowledgements The authors thank Bettina Braun and Astrid Bauer for excellent technical assistance and are grateful to Dr. Ursula Storch, Aaron Treder and Christian Hermann for providing the TRPC4 eGFP IRES plasmid as well as for help with the transfection experiments.

Author contributions All authors contributed to the study conception and design. Material preparation, data collection and analysis were performed by Christian Schremmer and Alexander Dietrich. The first draft of the manuscript was written by Alexander Dietrich and all authors commented on previous versions of the manuscript. All authors read and approved the final manuscript.

Funding Open Access funding enabled and organized by Projekt DEAL. This work was supported by the Deutsche Forschungsgemeinschaft (DFG, Research Training Group GRK 2338).

\section{Declarations}

Conflict of interest David Beech is an inventor on a patent to develop EA analogues as anti-cancer therapeutics: U.S. Patent No. 11,098,054 issued August 24, 2021. This patent can remain in force until July 5, 2038. Compounds for Treating Cancer. Inventors: John Beutler, Antonio Echavarren, William Chain, David Beech, Zhenhua Wu, JeanSimon Suppo, Fernando Bravo, Hussein Rubaiy.The other authors declare no conflict of interest.
Ethical standards All animal experiments were approved by the local authority (Regierung Oberbayern) and are, therefore, been performed in accordance with the ethical standards laid down in the 1964 Declaration of Helsinki and its later amendments.

Open Access This article is licensed under a Creative Commons Attribution 4.0 International License, which permits use, sharing, adaptation, distribution and reproduction in any medium or format, as long as you give appropriate credit to the original author(s) and the source, provide a link to the Creative Commons licence, and indicate if changes were made. The images or other third party material in this article are included in the article's Creative Commons licence, unless indicated otherwise in a credit line to the material. If material is not included in the article's Creative Commons licence and your intended use is not permitted by statutory regulation or exceeds the permitted use, you will need to obtain permission directly from the copyright holder. To view a copy of this licence, visit http://creativecommons.org/licenses/by/4.0/.

\section{References}

Akbulut Y, Gaunt HJ, Muraki K et al (2015) (-)-Englerin A is a potent and selective activator of TRPC4 and TRPC5 calcium channels. Angew Chem Int Ed Engl 54(12):3787-3791. https://doi.org/10. 1002/anie.201411511

Bendiks L, Geiger F, Gudermann T, Feske S, Dietrich A (2020) Storeoperated $\mathrm{Ca}(2+)$ entry in primary murine lung fibroblasts is independent of classical transient receptor potential (TRPC) channels and contributes to cell migration. Sci Rep 10(1):6812. https://doi. org/10.1038/s41598-020-63677-2

Capellini VK, Restini CB, Bendhack LM, Evora PR, Celotto AC (2013) The effect of extracellular $\mathrm{pH}$ changes on intracellular $\mathrm{pH}$ and nitric oxide concentration in endothelial and smooth muscle cells from rat aorta. PLoS ONE 8(5):e62887. https://doi.org/10.1371/ journal.pone.0062887

Carson C, Raman P, Tullai J et al (2015) Englerin A agonizes the TRPC4/C5 cation channels to inhibit tumor cell line proliferation. PLoS ONE 10(6):e0127498. https://doi.org/10.1371/journ al.pone. 0127498

Cheung SY, Henrot M, Al-Saad M et al (2018) TRPC4/TRPC5 channels mediate adverse reaction to the cancer cell cytotoxic agent (-)-Englerin A. Oncotarget 9(51):29634-29643. https://doi.org/ 10.18632/oncotarget.25659

Grant CV, Carver CM, Hastings SD et al (2019) Triple-negative breast cancer cell line sensitivity to englerin A identifies a new, targetable subtype. Breast Cancer Res Treat 177(2):345-355. https://doi. org/10.1007/s10549-019-05324-7

Ludlow MJ, Gaunt HJ, Rubaiy HN et al (2017) (-)-Englerin A-evoked cytotoxicity is mediated by $\mathrm{Na}+$ influx and counteracted by $\mathrm{Na}+/$ K+-ATPase. J Biol Chem 292(2):723-731. https://doi.org/10. 1074/jbc.M116.755678

Mizock BA, Falk JL (1992) Lactic acidosis in critical illness. Crit Care Med 20(1):80-93. https://doi.org/10.1097/00003246-19920 $1000-00020$

Muraki K, Ohnishi K, Takezawa A et al (2017) $\mathrm{Na}(+)$ entry through heteromeric TRPC4/C1 channels mediates (-)Englerin A-induced cytotoxicity in synovial sarcoma cells. Sci Rep 7(1):16988. https:// doi.org/10.1038/s41598-017-17303-3

Ratnayake R, Covell D, Ransom TT, Gustafson KR, Beutler JA (2009) Englerin A, a selective inhibitor of renal cancer cell growth, from Phyllanthus engleri. Org Lett 11(1):57-60. https://doi.org/10. 1021/ol802339w

Richardson DW, Wasserman AJ, Patterson JL Jr (1961) General and regional circulatory responses to change in blood $\mathrm{pH}$ and carbon 
dioxide tension. J Clin Invest 40:31-43. https://doi.org/10.1172/ JCI104234

Sourbier C, Scroggins BT, Ratnayake R et al (2013) Englerin A stimulates PKCtheta to inhibit insulin signaling and to simultaneously activate HSF1: pharmacologically induced synthetic lethality. Cancer Cell 23(2):228-237. https://doi.org/10.1016/j.ccr.2012. 12.007

Sundivakkam PC, Freichel M, Singh V et al (2012) The Ca(2+) sensor stromal interaction molecule 1 (STIM1) is necessary and sufficient for the store-operated $\mathrm{Ca}(2+)$ entry function of transient receptor potential canonical (TRPC) 1 and 4 channels in endothelial cells. Mol Pharmacol 81(4):510-526. https://doi.org/10.1124/mol.111. 074658

Thorball N (1981) FITC-dextran tracers in microcirculatory and permeability studies using combined fluorescence stereo microscopy, fluorescence light microscopy and electron microscopy. Histochemistry 71(2):209-233. https://doi.org/10.1007/BF00507826

Tiruppathi C, Freichel M, Vogel SM et al (2002) Impairment of storeoperated $\mathrm{Ca} 2+$ entry in TRPC4(-/-) mice interferes with increase in lung microvascular permeability. Circ Res 91(1):70-76

Weber J, Rajan S, Schremmer C et al (2020) TRPV4 channels are essential for alveolar epithelial barrier function as protection from lung edema. JCI Insight. https://doi.org/10.1172/jci.insig ht. 134464

Weissmann N, Dietrich A, Fuchs B et al (2006) Classical transient receptor potential channel 6 (TRPC6) is essential for hypoxic pulmonary vasoconstriction and alveolar gas exchange. Proc Natl Acad Sci USA 103(50):19093-19098

Weissmann N, Sydykov A, Kalwa H et al (2012) Activation of TRPC6 channels is essential for lung ischaemia-reperfusion induced oedema in mice. Nat Commun 3:649. https://doi.org/10.1038/ ncomms 1660

Wu Z, Zhao S, Fash DM, Li Z, Chain WJ, Beutler JA (2017) Englerins: a comprehensive review. J Nat Prod 80(3):771-781. https://doi. org/10.1021/acs.jnatprod.6b01167

Publisher's Note Springer Nature remains neutral with regard to jurisdictional claims in published maps and institutional affiliations. 